\title{
Ectopic expression of the chemokine CXCL17 in colon cancer cells
}

\author{
Lina Ohlsson ${ }^{1}$, Marie-Louise Hammarström ${ }^{1}$, Gudrun Lindmark² ${ }^{2}$ Sten Hammarström ${ }^{1}$ and Basel Sitohy ${ }^{\star, 3}$ \\ ${ }^{1}$ Department of Clinical Microbiology, Section of Immunology, Umeå University, SE-90185 Umeå, Sweden; ${ }^{2}$ Department of \\ Surgery, Helsingborg Hospital, SE-25187 Helsingborg, Sweden and ${ }^{3}$ Department of Radiation Sciences, Section of Oncology, \\ Umeå University, SE-90185 Umeå, Sweden
}

Background: The novel chemokine CXCL17 acts as chemoattractant for monocytes, macrophages and dendritic cells. CXCL17 also has a role in angiogenesis of importance for tumour development.

\begin{abstract}
Methods: Expression of CXCL17, CXCL10, CXCL9 and CCL2 was assessed in primary colon cancer tumours, colon carcinoma cell lines and normal colon tissue at mRNA and protein levels by real-time GRT-PCR, immunohistochemistry, two-colour immunofluorescence and immunomorphometry.

Results: CXCL17 mRNA was expressed at 8000 times higher levels in primary tumours than in normal colon $(P<0.0001)$. CXCL17 protein was seen in $17.2 \%$ of cells in tumours as compared with $0.07 \%$ in normal colon $(P=0.0002)$. CXCL10, CXCL9 and CCL2 mRNAs were elevated in tumours but did not reach the levels of CXCL17. CXCL17 and CCL2 mRNA levels were significantly correlated in tumours. Concordant with the mRNA results, CXCL10- and CXCL9-positive cells were detected in tumour tissue, but at significantly lower numbers than CXCL17. Two-colour immunofluorescence and single-colour staining of consecutive sections for CXCL17 and the epithelial cell markers carcinoembryonic antigen and BerEP4 demonstrated that colon carcinoma tumour cells indeed expressed CXCL17.
\end{abstract}

Conclusions: CXCL17 is ectopically expressed in primary colon cancer tumours. As CXCL17 enhances angiogenesis and attracts immune cells, its expression could be informative for prognosis in colon cancer patients.

Chemokines are chemotactic cytokines and have been classified as homeostatic or inflammatory on the basis of the stimuli regulating their production (Zlotnik and Yoshie, 2012). Chemokines bind receptors belonging to class A G-protein-coupled receptor superfamily triggering signalling cascades and promoting multiple cellular functions (Vassilatis et al, 2003). In addition to recruiting leukocytes to the site of inflammation, chemokines are involved in the growth and progression of many tumour types. They can modulate tumour progression via regulating angiogenesis through maintaining the balance between angiogenic and angiostatic chemokines (Rotondi et al, 2007).

CXCL9 and CXCL10, both ligands to the receptor CXCR3, have been implicated as angiostatic chemokines that attract antitumoural dendritic cells, T lymphocytes and natural killer cells to the site of tumour development. These chemokines have previously been shown to be constitutively expressed by human colon cancer cell lines and to be upregulated by treating the cells with the cytokines interferon- $\gamma$, interleukin- $1 \beta$ and tumour necrosis factor- $\alpha$ (Dwinell et al, 2001). CXCL9 and CXCL10 were also demonstrated in colorectal tumour tissues (Erreni et al, 2009). CCL2 is expressed in colorectal cancer including colorectal cancer cell lines (Jung et al, 1995; Chun et al, 2015), and recent data indicate that CCL2 has a pro-neoplastic role by regulating myeloidderived suppressor cells (Chun et al, 2015).

CXCL17 is a novel 119 amino acid CXC chemokine whose receptor, GPR35/CXCR8, was recently revealed (Lee et al, 2013; Maravillas-Montero et al, 2015). It was reported to be expressed in breast cancer and probably also in colon cancer (Weinstein et al, 2006; Matsui et al, 2012) to act as a chemoattractant for monocytes, macrophages and mature- and immature dendritic

*Correspondence: Dr B Sitohy; E-mail: basel.sitohy@onkologi.umu.se

Received 30 September 2015; revised 10 December 2015; accepted 16 December 2015; published online 18 February 2016

(c) 2016 Cancer Research UK. All rights reserved 0007-0920/16 
cells (Weinstein et al, 2006; $\mathrm{Mu}$ et al, 2009), and to have an important role in angiogenesis for tumour development (Weinstein et al, 2006; Matsui et al, 2012). CXCL17 expression was shown to be tightly co-regulated with vascular endothelial growth factor expression (Weinstein et al, 2006; Lee et al, 2013). Moreover, CXCL17 was demonstrated to recruit neutrophils to tumour sites and promote tumorigenesis through angiogenesis in a mouse model (Matsui et al, 2012).

In hepatic carcinoma, CXCL17 was reported to be produced mainly by tumour-infiltrating neutrophils and occasionally by the tumour cells (Li et al, 2014). CXCL17 was suggested to be an independent indicator for poor prognosis both overall survival and progression-free survival, because its expression correlated with unfavourable immune infiltration (Li et al, 2014). In another study, CXCL17 was suggested to be involved in antitumour immune response during pancreatic carcinogenesis through triggering the accumulation of dendritic cells at the tumour site promoting tumour cells susceptibility to cytotoxic T-cell-mediated cytolysis (Hiraoka et al, 2011).

In this study, we have investigated the expression of CXCL17 in primary colon tumours, colon cancer cell lines and normal colon tissue at the mRNA and protein levels, and firmly establish that CXCL17 is ectopically expressed in colon cancer cells. For comparison, we also analysed the expression of CXCL9, CXCL10 and CCL2.

\section{MATERIALS AND METHODS}

Patients and tissue specimens for mRNA analysis. Primary tumour specimens from 32 colon cancer patients (13 men and 19 women; mean age 72 years, range $43-86$ years) were retrieved after surgery. None of the patients received treatment before surgery. Twelve patients were in stage I (T1-2N0M0), 10 in stage II (T3-4N0M0), 8 in stage III (anyTN1-2M0) and 2 in stage IV (anyTanyNM1). Primary tumour stage distribution (pT1-pT4) was $2,10,10$ and 10, respectively. The tumour samples, $\sim 0.5 \times 0.5 \times 0.5 \mathrm{~cm}$ in size, were collected immediately after resection, snap-frozen and stored at $-70{ }^{\circ} \mathrm{C}$ until RNA extraction. Normal colon samples retrieved from the proximal or distal resection margin of colon cancer tumours were also collected from 30 patients (mean age 72 , range $57-85$ years) and treated the same way.

Cell lines and peripheral blood mononuclear cells. The human colon carcinoma cell lines LS174T, HT29, T84, HCT8 and CaCo2 were used (Ohlsson et al, 2012). Peripheral blood mononuclear cells (PBMCs) were isolated from healthy adults by FicollIsopaque gradient centrifugation. Polyclonal activation of PBMCs was performed as described (Ohlsson et al, 2012).

Patients and tissue specimens for immunohistochemistry. Primary tumour tissue specimens from 10 colon cancer patients (4 men and 6 women; mean age 72 years) obtained after surgery were studied. None of the patients received treatment before surgery. One tumour was in stage I, three in stage II, four in stage III and two in stage IV. The localisation of the tumours was caecum (three patients), ascending colon (three patients), transverse colon (two patients) and sigmoid colon (two patients). Primary tumour stage distribution (pT2-pT4) was 1, 6 and 3, respectively. Normal colon tissue specimens were also obtained from 10 colon cancer patients ( 5 men and 5 women; mean age 62 years) and were taken distant to any macroscopically detectable lesions. The localisation of the normal colonic specimens was caecum (two patients), ascending colon (two patients), transverse colon (one patient) and sigmoid colon (five patients).
RNA preparation. Total RNA was extracted using the acidguanidine-phenol-chloroform method as described earlier (Ohlsson et al, 2012).

Real-time qRT-PCR. The commercially available TaqMan Gene Expression Assays Hs01650998_m1, Hs00171042_m1, Hs00171065_m1, Hs00234140_m1, Hs01567026_m1 and Hs00154355_m1 (Applied Biosystems, Foster City, CA, USA) in combination with TaqMan EZ technology (Applied Biosystems) were used to determine the expression levels of CXCL17, CXCL10, CXCL9, CCL2, CD86 and CD68, respectively. The RT-PCR profile was $50{ }^{\circ} \mathrm{C}$ for $2 \mathrm{~min}, 60^{\circ} \mathrm{C}$ for $30 \mathrm{~min}$ and $95^{\circ} \mathrm{C}$ for $5 \mathrm{~min}$ followed by 45 cycles of $95^{\circ} \mathrm{C}$ for $20 \mathrm{~s}$ and $60^{\circ} \mathrm{C}$ for $1 \mathrm{~min}$. Emission from the released reporter dye was measured by the ABI Prism 7700 Sequence Detection System (Applied Biosystems). All qRT-PCR analyses were carried out in triplicates. The concentration of $18 \mathrm{~S}$ rRNA was determined in each sample by real-time qRT-PCR (Applied Biosystems) for normalisation of chemokine mRNA levels (Bas et al, 2004). Chemokine expression levels in primary tumours and cell lines are expressed as relative quantity (RQ) calculated according to the equation: $2^{\wedge}-(\Delta c t$ of the sample - the median $\Delta c t$ value of the normal colon tissue samples). $\Delta \mathrm{ct}$ is the ct value of the chemokine mRNA minus the ct value of $18 \mathrm{~S}$ rRNA in the same sample. Concentrations of mRNA for carcinoembryonic antigen (CEA) were determined by using a $\mathrm{qRT}-\mathrm{PCR}$ constructed in the laboratory using the TaqMan EZ technology (Applied Biosystems) and an external RNA copy standard (Öberg et al, 2004). CEA mRNA levels were estimated by dividing the CEA mRNA concentration with the concentration of $18 \mathrm{~S}$ rRNA in the same sample, as determined by qRT-PCR for $18 \mathrm{~S}$ rRNA (Applied Biosystems) and an external standard of total RNA from polyclonally activated human PBMCs. An amount of $1 \mathrm{pg}$ RNA is defined as one unit (U) of $18 \mathrm{~S}$ rRNA that corresponds approximately to 1 epithelial cell (Fahlgren et al, 2003).

Antibodies and substrate. For immunohistochemistry (IHC), the monoclonal antibodies (mAbs) were anti-CXCL17 (MAB4207, clone 422208; R\&D Systems, Minneapolis, MN, USA), antiCXCL10 (NB600-1426; Novus, Littleton, CO, USA), anti-CXCL9 (MAB392, clone 49106; R\&D Systems) and anti-CEA mAb, clone II-7 (Dako, Glostrup, Denmark). Mouse IgG, ready to use (Dako), served as negative control. Anti-mouse Ig ImmPress enhancement reagents kit was purchased from Vector Laboratories (Burlingame, CA, USA). The substrate used was 3,3'-diaminobenzidine (DAB; Vector Laboratories).

For immunofluorescence, the mAbs were FITC-conjugated antiepithelial cell mAb BerEP4 (F0860, lot 00059670; Dako) and unconjugated anti-CXCL17 mAb. Alexa Fluor 594-conjugated goat anti-mouse IgG (ab150116, Abcam, Cambridge, MA, USA) was used as secondary antibody. Anti-CEA mAb was used as a positive control for indirect staining, and FITC-conjugated mouse IgG2b (X0959; Dako) was used as a negative control.

Immunohistochemistry. Fresh tissue samples were rinsed with cold phosphate-buffered saline (PBS), snap-frozen in iso-pentane pre-cooled in liquid nitrogen and stored at $-70{ }^{\circ} \mathrm{C}$. Frozen tissue was cut into $4-6-\mu \mathrm{m}$-thick sections with a cryo-microtome (MICROM HM505E, Thermo Fisher, Waltham, MA, USA). Briefly, as described elsewhere (Sitohy et al, 2008), the sections were fixed with $4 \%$ paraformaldehyde for $15 \mathrm{~min}$ before air-drying, rehydration in $\mathrm{PBS}$ and immersion in PBS containing $0.03 \% \mathrm{H}_{2} \mathrm{O}_{2}$ and $2 \mathrm{mM} \mathrm{NaN}_{3}$ at $37^{\circ} \mathrm{C}$ to quench endogenous peroxidase activity. Thereafter, the sections were incubated with $0.2 \%$ bovine serum albumin in PBS followed by ImmPress ready-to-use horse blocking serum (Vector Laboratories) at room temperature to block non-specific binding sites. Subsequently, the sections were incubated with primary $\mathrm{mAbs}$ for $1 \mathrm{~h}$ at room temperature followed by $1 \mathrm{~h}$ incubation with ImmPress anti-mouse Ig. 
The bound peroxidase was revealed by incubation with $0.05 \% \mathrm{DAB}$ and $0.03 \% \mathrm{H}_{2} \mathrm{O}_{2}$ in $0.05 \mathrm{M}$ Tris buffer ( $\mathrm{pH}$ 7.6) at room temperature, and was counterstained with methyl green. AntiCEA mAb was used as a positive control, and mouse IgG served as a negative control.

Two-colour immunofluorescence. Sections of tumour tissues were cut and fixed as described above, and were incubated with the anti-CXCL17 mAb, followed by the Alexa Fluor 594conjugated goat anti-mouse Ig (red). Subsequently, the sections were incubated with FITC-conjugated BerEP4 (green). Doublepositive cells develop a yellow-orange colour. The sections were then mounted with 6-diamidino-2-fenylindole (Thermo Fisher). Microscopy was done using a Nikon fluorescence microscope and images were analysed with NIS elements software.

Immunomorphometry. Quantification of number of cells was performed according to Weibel (1979), analysing the expression of the three chemokines in tumour cells and in the surrounding stroma in comparison with controls. Twenty randomly chosen ocular fields were counted for each marker in each compartment. One observer (BS) performed the analyses and the slides were coded to avoid personal bias. An integrating cooled colour 3CCD camera (Colour Chilled 3 CCD Hamamatsu CameraC5810; Hamamatsu Photonics, Hamamatsu City, Japan) was used on a standard light microscope combined with a computer image analysis system (LeicaQWin, Leica Imaging Systems, Cambridge, UK) with an interactive, computerised morphometry programme. Microscopic fields were selected randomly using $\times 40$ objective and transferred to the screen, onto which a regular 121-points lattice was superimposed. Points outside the concerned tissue compartment and empty spaces were not included in the calculation. Positive cells located in the coarse points were counted, and the ratio between the number of points covering positive cells and the total number of points covering the tissue under investigation was calculated for each microscopic field.

Statistical analysis. The statistical significance of differences in mRNA levels and number of cells expressing different chemokines in primary tumour tissue compared with normal colon tissue was calculated using the two-tailed Mann-Whitney rank sum test. Correlation between chemokine mRNA levels was analysed using the non-parametric Spearman correlation coefficient. Descriptive values are expressed as mean \pm s.e.m. The software utilised for statistical calculations was GraphPad Prism 5 (Graphpad Software, San Diego, CA, USA).

Ethical considerations. Tumour samples were obtained after patient's consent. The Local Ethics Research Committee of the
Medical Faculty, Umeå University approved this study (registration number 03-503; date of approval 3 December 2003).

\section{RESULTS}

Chemokine mRNA levels in primary colon tumours, colon carcinoma cell lines and PBMCs. Figure 1 shows the relative mRNA levels of CXCL17, CXCL10, CXCL9 and CCL2 in 32 primary tumours and 30 normal colon samples in which the median value of the control group is set to 1 . The difference between the tumour samples and the controls was highly significant for all four chemokine mRNAs. For CXCL17, the difference between the median values of tumour and normal tissue was 8000 -fold (Table 1). For CCL2, it was 400 -fold, whereas for CXCL10 and CXCL9 it was only 70 - and 40-fold, respectively (Table 1). Interestingly, CXCL17 mRNA levels correlated with CCL2 mRNA levels $(P=0.056, r=0.34$; Figure 2). As can be seen in the graph, the samples fall into two separate groups with high and low CXCL17 expression levels. Higher significance was obtained if each group was analysed separately (high CXCL17 mRNA group: $P=0.013, r=0.48$; low CXCL17 mRNA group:

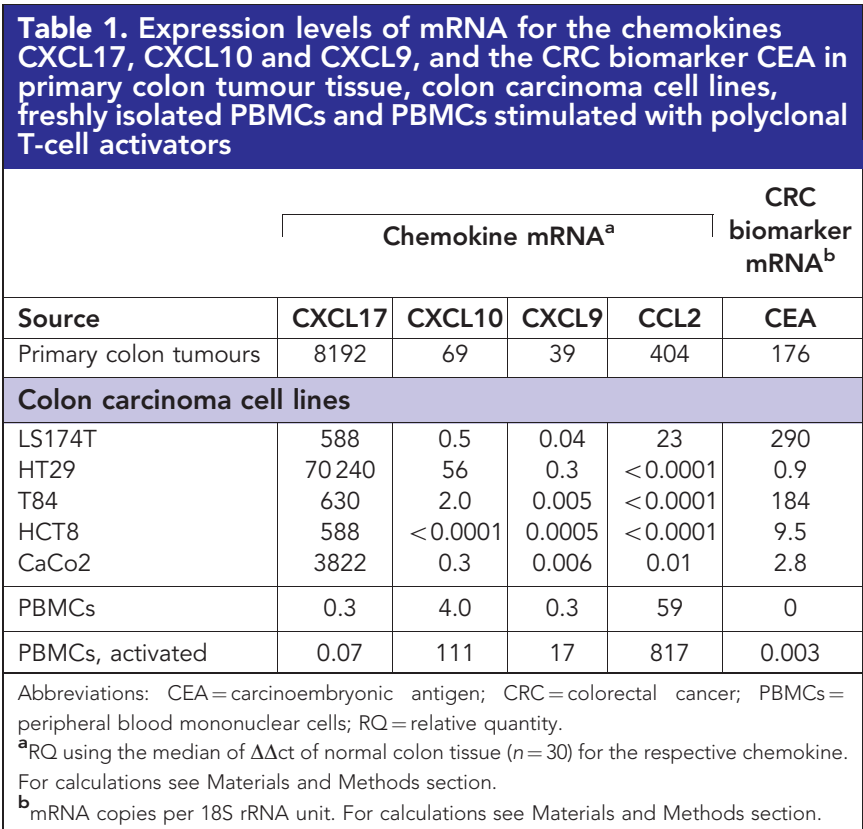
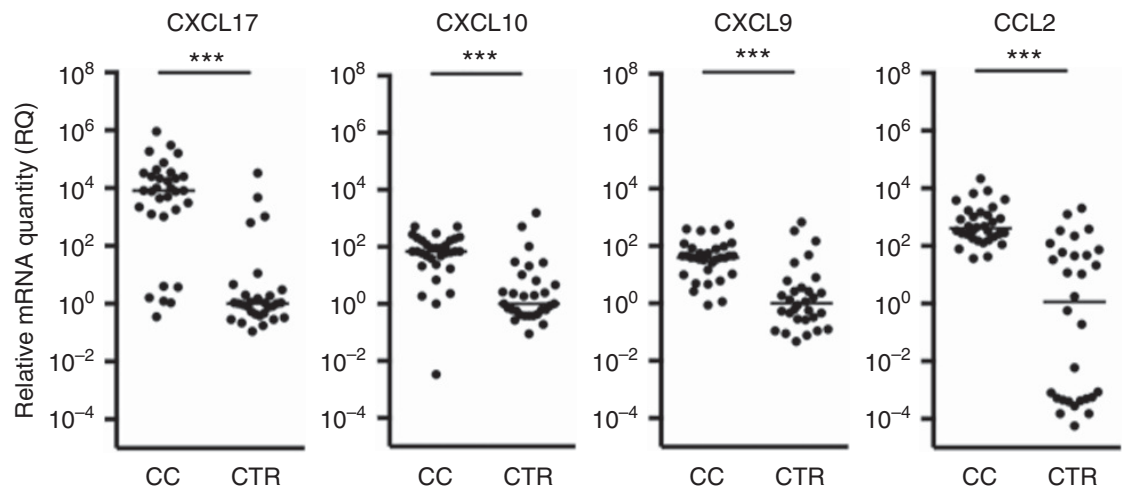

Figure 1. Relative mRNA levels of CXCL17, CXCL10, CXCL9 and CCL2 in primary colon cancer tissue (CC, stages I-IV; $n=32)$ and normal colon retrieved from the proximal or distal resection margins $(C T R ; n=30)$. Relative quantity $(R Q)$ was calculated as described in Materials and Methods section. Statistically significant differences are depicted, ${ }^{\star \star \star} P<0.0001$. 


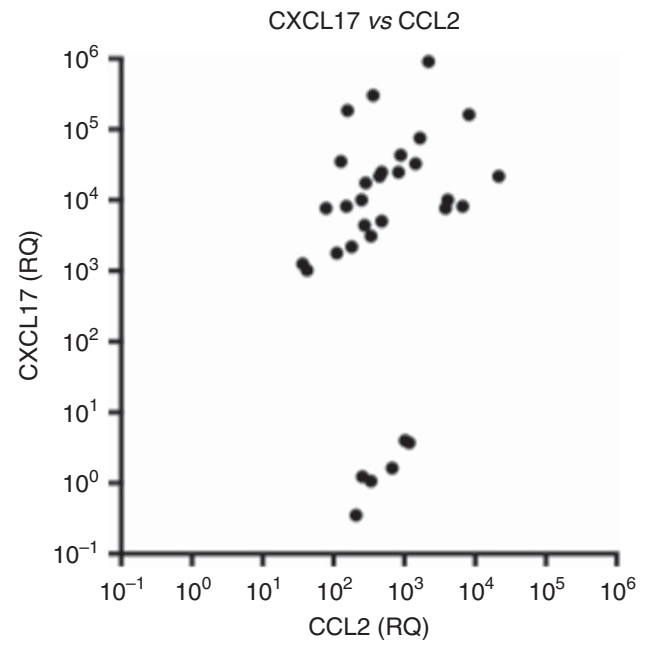

Figure 2. Correlation between mRNA levels of CXCL17 and CCL2 in primary colon cancer tissue (stages I-IV; $n=32$ ). Relative quantity (RQ) was calculated as described in Materials and Methods section.

$P=0.033, \quad r=0.88)$, indicating that there are two different cell populations expressing these chemokines. There was no correlation between CXCL17 mRNA levels in primary tumours compared with either CXCL9 or CXCL10 levels $(P>0.05, r=0.11$ and 0.08 , respectively), whereas there was a strong correlation between mRNA levels of CXCL9 and CXCL10 $(P<0.0001, r=0.80)$. CXCL17 mRNA levels in primary tumours were not correlated to tumour (pT)-stage or TNM-stage (median RQ value for stages I + II was 10085 , and 3086 for stages III + IV; $P=0.25$ ). Low levels of CXCL17 mRNA (6 out of 32 ) could not be assigned to a particular tumour (pT)-stage (data not shown) or TNM-stage ( 4 out of 22 in stages I + II and 2 out of 10 in stages III + IV).

Table 1 also depicts the chemokine mRNA levels in five colon carcinoma cell lines, freshly isolated PBMCs, activated PBMCs and the mRNA levels of the colorectal cancer biomarker CEA in these cell types. CXCL17 mRNA was expressed at high levels in all colon carcinoma cell lines and at very high levels in HT29 cells, but essentially not in PBMCs. It is interesting to note that the expression levels in these cell lines are similar to the median level of primary tumours. Although CCL2 mRNA was expressed at a fairly high median level in primary colon tumours, it was only expressed in 1 out of 5 colon carcinoma cell lines. In contrast to CXCL17 mRNA, CCL2 mRNA was highly expressed in PBMCs, particularly in activated PBMCs. CXCL10 and CXCL9 mRNAs were, with the exception of CXCL10 in HT29 cells and T84 cells, very weakly expressed in the colon carcinoma cell lines. In contrast to CXCL17, the highest expression levels for these chemokines were seen in activated PBMCs.

Expression of CXCL17-, CXCL10- and CXCL9 proteins in colon cancer tumours and normal colon tissue as determined by two-colour immunofluorescence and IHC. To ascertain that tumour cells indeed expressed CXCL17 protein, we performed twocolour immunofluorescence experiments using anti-CXCL17 (Figure $3 \mathrm{~A}$ and $\mathrm{B}$; red) and the anti-epithelial cell mAb BerEP4 (Figure $3 \mathrm{C}$ and $\mathrm{D}$; green). The overlay pictures (Figure $3 \mathrm{E}$ and F; yellow) demonstrate that a large number of primary tumour cells expressed both markers. Figure 4 shows immunoperoxidase staining of sections of primary colon tumours and normal colon tissue stained with anti-CXCL17 (Figure 4A-C) and anti-CEA (Figure 4D and E) $\mathrm{mAbs}$, and Figure $5 \mathrm{~A}-\mathrm{C}$ shows staining with anti-CXCL10 $\mathrm{mAb}$. Intense staining of tumour cells and no or only weak staining of normal colon epithelial cells by antibodies against the two chemokines
A

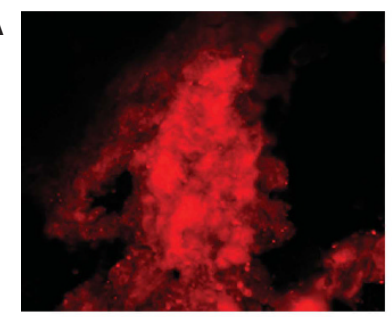

C

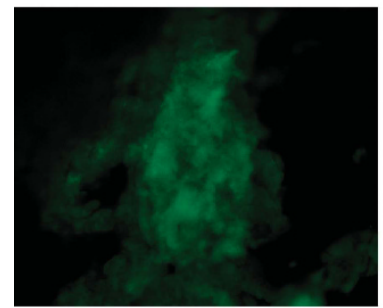

E

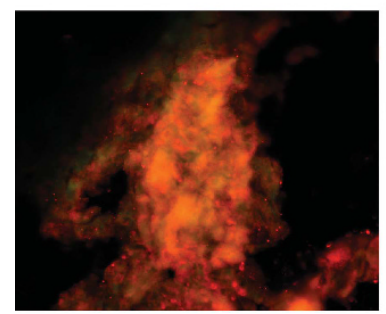

B

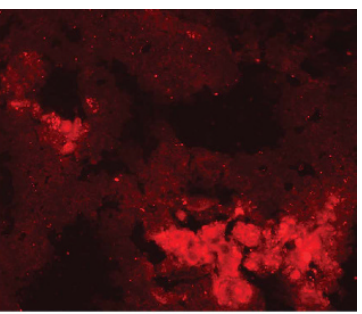

D

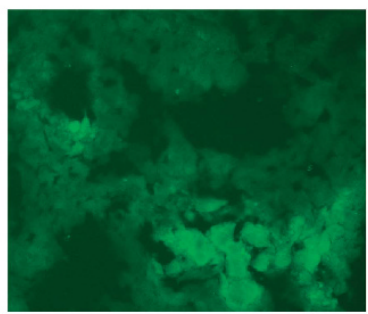

$\mathbf{F}$

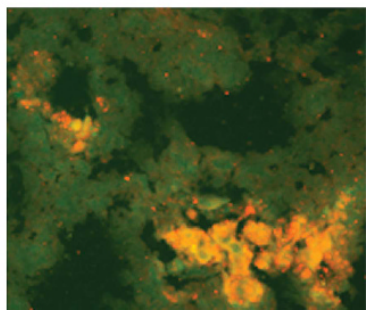

Figure 3. Two-colour immunofluorescence staining of primary colon cancer tissue with anti-CXCL17 mAb and BerEP4. Two different tissue sections are shown. Section one $(\mathbf{A}, \mathbf{C}, \mathbf{E})$ and section two $(\mathbf{B}, \mathbf{D}, \mathbf{F})$. (A, B) Anti-CXCL17 mAb; red colour. (C, D) BerEP4 mAb; green colour. (E, F) Overlay; yellow colour of double-stained areas. Magnification: $\times 200$. Section one shows many double-positive cells, whereas section two shows relatively few double-positive cells.

was seen. Similarly, anti-CEA mAb stained the tumour cells. Figure $4 \mathrm{~A}$ and $\mathrm{B}$, and $\mathrm{D}$ and $\mathrm{E}$ are consecutive sections demonstrating that the tumour cells express both CXCL17 and CEA.

Figure 6 shows the results of quantification of number of stained cells according to Weibel (1979). Only low frequencies of stained cells were seen in normal colon. CXCL9 was expressed mainly in the epithelial cells at $1 \%$ and only at $0.5 \%$ in the lamina propria. Conversely, the expression of CXCL10 and CXCL17 was mainly observed in the lamina propria (at $0.4 \%$ and $0.2 \%$, respectively), and only very few positive cells were detected in the epithelium $(0.1 \%$ and $0.07 \%$, respectively; Figure 6$)$.

CXCL17-, CXCL10- and CXCL9-positive cells were observed at significantly higher frequencies in colon cancer compared with controls and were most frequent among tumour cells compared with tumour stroma. Most interestingly, $17.2 \%$ of the tumour cells were CXCL17 positive. CXCL9- and CXCL10-positive cells constituted $3.7 \%$ and $5.3 \%$, respectively, of the tumour cells. CXCL17-positive cells in the stroma constituted 2.7\%, whereas CXCL9- and CXCL10-positive cells were infrequent $(0.4 \%$ and $0.1 \%$, respectively). The differences in frequencies between tumour and normal epithelium were highly significant $(P=0.0002$ for CXCL17, $P=0.0002$ for CXCL10, and $P=0.0088$ for CXCL9). The frequency of CXCL17 was significantly increased in the tumour stroma compared with the normal lamina propria $(P=0.0002)$, but no significant differences were found for CXCL9 and CXCL10 ( $P=0.28$ and $P=0.5$, respectively). Finally, we found that the frequency of CXCL17-stained cells was significantly higher than both CXCL9- and CXCL10-stained cells in both the tumour compartment $(P=0.0003$ and $P=0.0005$ respectively) and also in the stroma ( $P=0.0011$ and $P=0.0002$, respectively). 

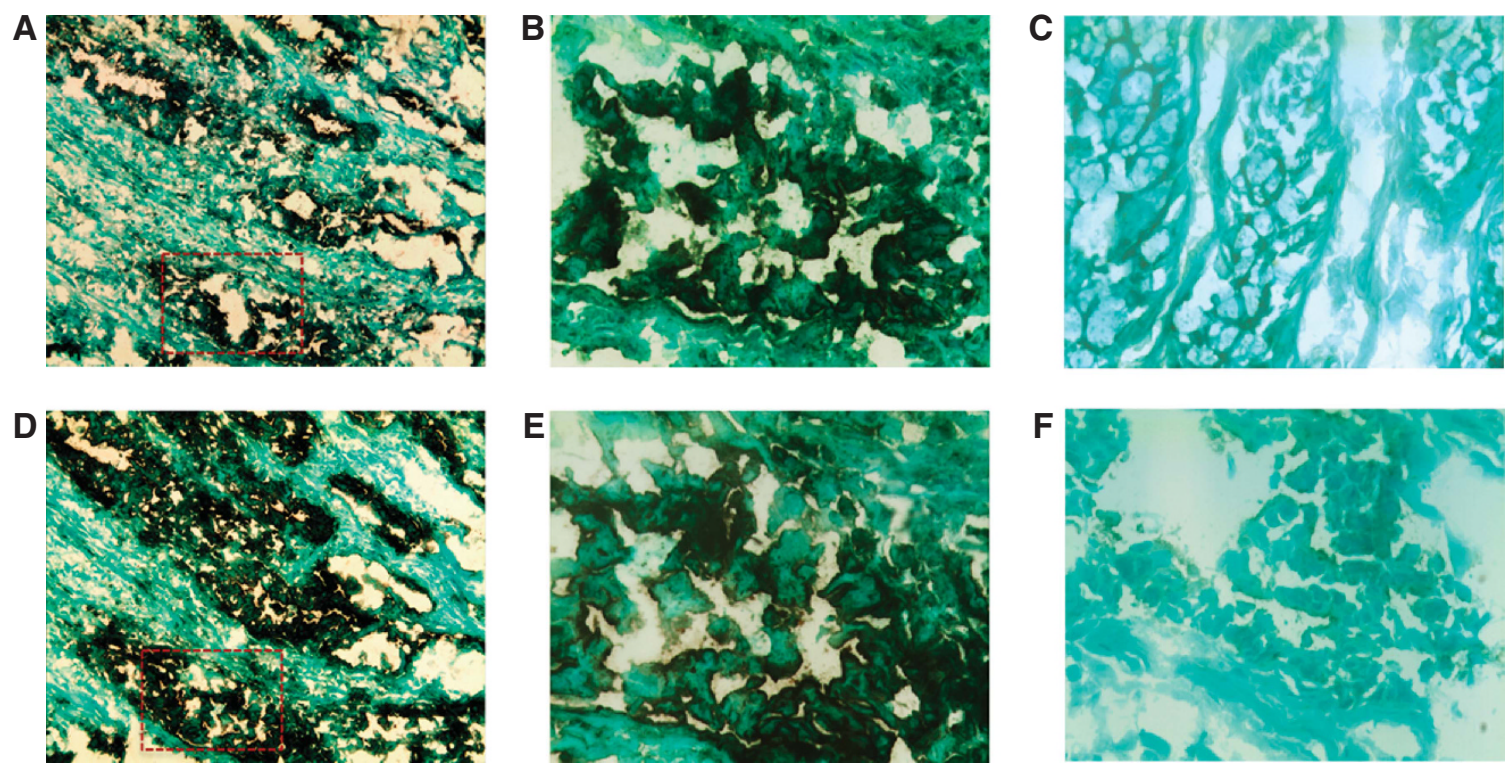

Figure 4. Immunoperoxidase staining of tissue sections of primary colon cancer tumour and normal colon with anti-CXCL17 mAb and anti-CEA mAb. (A) Anti-CXCL17 staining of primary tumour at low magnification, $\times 32$. (B) Anti-CXCL17 staining of primary tumour at high magnification, $\times 200$. The area enlarged is indicated in $\mathbf{A}$. (C) Anti-CXCL17 staining of normal colon at low magnification, $\times 32$. (D) Anti-CEA staining of primary tumour at low magnification, $\times 32$. (E) Anti-CEA staining of primary tumour at high magnification, $\times 200$. The area enlarged is indicated in $\mathbf{D}$. (F) Conjugate control at high magnification, $\times 200$. Note that $\mathbf{A}$ and $\mathbf{D}$, and $\mathbf{B}, \mathbf{E}$ and $\mathbf{F}$ are consecutive sections.
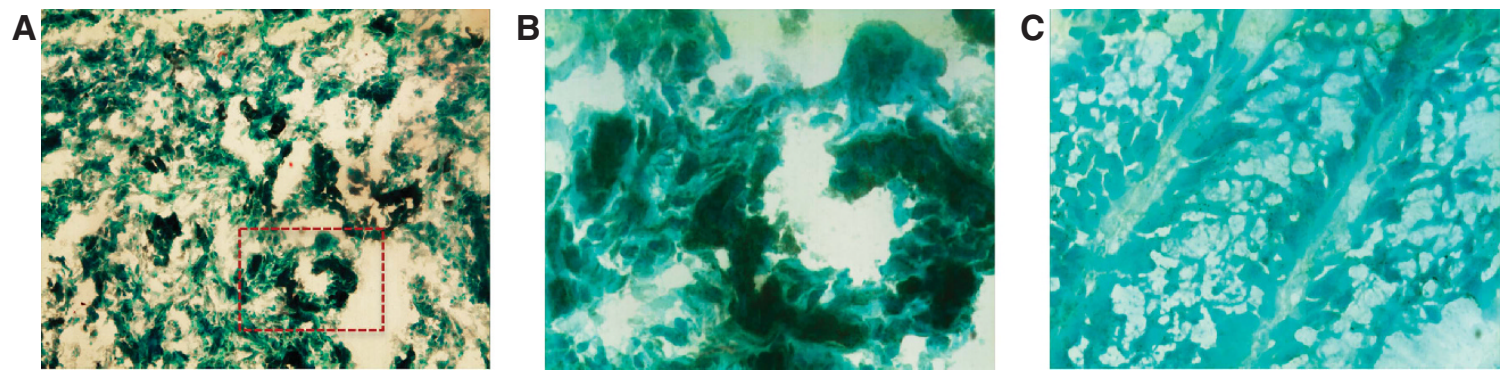

Figure 5. Immunoperoxidase staining of tissue sections of primary colon cancer tumour and normal colon with anti-CXCL10 mAb. (A) Anti-CXCL10 staining of primary tumour at low magnification, $\times 32$. (B) Anti-CXCL10 staining of primary tumour at high magnification, $\times 200$. The enlarged area is indicated in A. (C) Anti-CXCL10 staining of normal colon at low magnification, $\times 32$.

Correlation between mRNAs for CXCL17 and CCL2, and mRNAs for markers of myeloid cells. As CXCL17 and CCL2 are known to recruit myeloid cells (macrophages/dendritic cells/ antigen-presenting cells (APCs)), we investigated whether there was a relationship between mRNA levels for the myeloid cell markers CD86 and $\mathrm{CD} 68$, and the two chemokines in primary colon tumours. Both CXCL17 and CCL2 correlated with CD86 $(P=0.06, r=0.4$; and $P=0.02 ; \mathrm{r}=0.4$, respectively), suggesting that these two chemokines recruit CD86 expressing cells to the tumour. In contrast, no correlation was found between CXCL17 or CCL2 and CD68 $(P=0.8, r=0.03$; and $P=0.9, r=0.007$, respectively).

\section{DISCUSSION}

This study shows that (1) colon tumour cells, positive for the epithelial cell markers BerEP4 and CEA, express the chemokine CXCL17 as revealed by two-colour immunofluorescence and immunohistochemical staining of consecutive tissue sections; (2) at least $80 \%$ of primary colon tumours and 5 out of 5 colon carcinoma cell lines express high levels of CXCL17 mRNA as determined by qRT-PCR; and (3) 15-20\% of the cells in primary tumours express CXCL17 protein as revealed by immunomorphometry. In contrast, normal colon tissue expressed only marginal levels of CXCL17 mRNA, and only $0.07 \%$ of the normal epithelial cells were CXCL17 positive. Taken together, these results demonstrate that CXCL17 is ectopically expressed in primary colon tumours. Lack of expression in normal colon is in line with recent data in the Human Protein Atlas, which demonstrates that CXCL17 mRNA is expressed in normal stomach, oesophagus and salivary gland, but not in the small- or large bowel (Uhlen et al, 2014). CXCL17 appears to be relatively tumour cell specific in contrast to CXCL10, CXCL9 and CCL2 because CXCL17 mRNA was only expressed at very low levels in freshly isolated PBMCs and activated PBMCs, whereas the former three chemokine mRNAs were expressed at comparable levels in primary tumours and in activated PBMCs (Table 1). Moreover, different cellular source for CXCL17 compared with CXCL10 and CXCL9 was underscored by the lack of correlation between their mRNA levels. CXCL9 is perhaps not a product of the tumour cells, but it may have its origin in infiltrating immune cells, as it was hardly at all expressed in any of the five established colon carcinoma cell lines. 

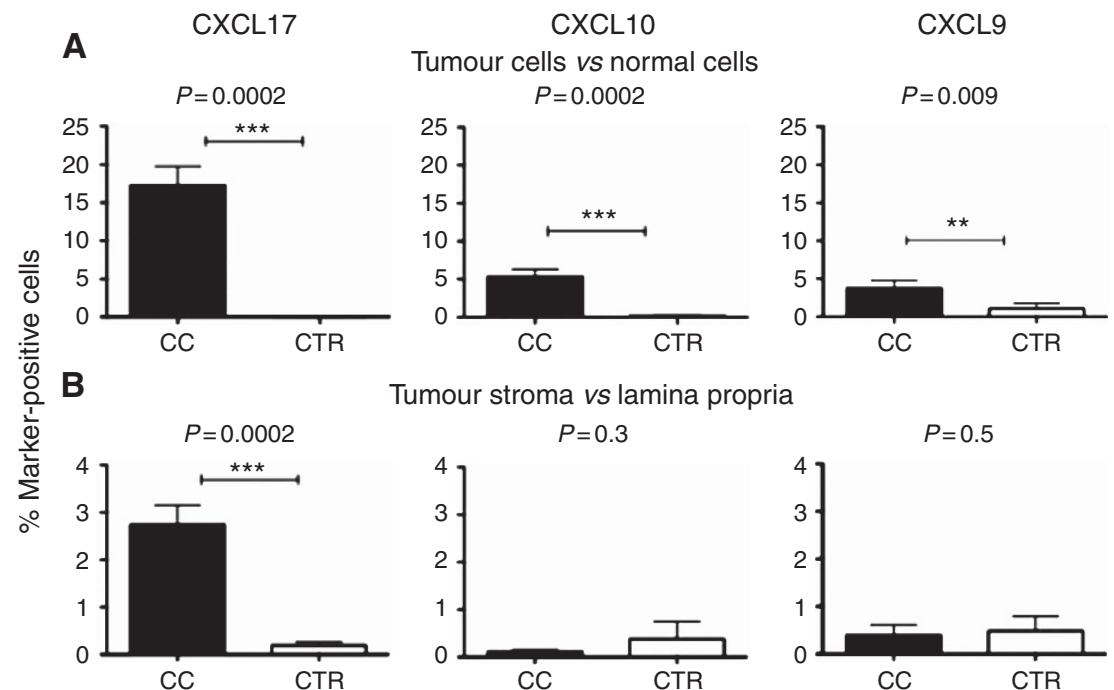

Tumour stroma vs lamina propria
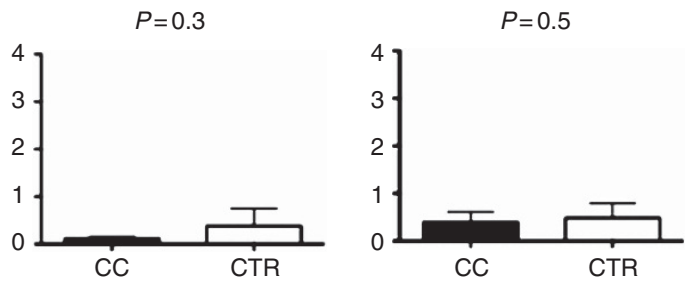

Figure 6. Frequencies of CXCL17-, CXCL10- and CXCL9-positive cells in primary colon cancer tissue (CC) and normal colon tissue (CTR) as determined by immunomorphometry according to Weibel (1979). (A) Tumour cells compared with normal epithelial cells. (B) Tumour stroma compared with lamina propria in normal tissue. Ten primary tumours, stages I-IV and 9-10 normal colon samples were analysed. Bars represent mean +1 s.e.m. $P$-values for comparison between tumour and normal tissue by two-sided Mann-Whitney $t$-test are given. ${ }^{\star \star \star} P<0.001$ and $\star \star P<0.01$

Only a few primary tumour samples expressed low CXCL17 mRNA levels. This could be owing to difficulties in obtaining a representative sample of a large heterogeneous tumour. The alternative that expression of CXCL17 mRNA was related to pTstage or TNM-stage was not seen in this clinical material. However, it is interesting to note that the same cell population was identified by the chemokine CCL2 (Figure 2). Whether these cells are tumour cells, infiltrating immune cells or other non-tumour cells remain to be established.

We noted that CXCL17 mRNA was correlated to CD86 mRNA but not to CD68 mRNA. CD86 is primarily a marker for APCs, whereas CD68 is expressed on several different cell populations including blood monocytes, tissue macrophages, lymphocytes and fibroblasts (Gottfried et al, 2008; Seliger et al, 2008). A probable interpretation of this finding would be that CXCL17 contributes to infiltration of colon carcinoma tumours by APCs.

Expression of CXCL17 in colon cancer differs markedly from the expression of this chemokine in hepatic carcinoma-in colon cancer the tumour cells are the main producers, whereas in hepatic carcinoma it is infiltrating neutrophils (Li et al, 2014).

Our results suggest that CXCL17 could be an indicator of poor prognosis in colon cancer similar to what was demonstrated in hepatic carcinoma (Li et al, 2014). Thus, CXCL17 has potential of becoming an important biomarker for colon cancer possibly both for diagnosis and prognosis. Its expression in colon cancer cells suggests a role in tumour progression perhaps by stimulating local angiogenesis. To what extent CXCL17 contributes to the recruitment of immune cells to the tumour site, and if so whether they counteract or promote tumour growth, remains to be elucidated. CXCL17 also acts as an antimicrobial peptide with bactericidal effects (Burkhardt et al, 2012). It is interesting to speculate that a trigger to innate antibacterial response by epithelial cells also can lead to angiogenesis and consequent growth support for tumour cells.

\section{ACKNOWLEDGEMENTS}

This work was financially supported by grants from the Swedish Research Council (BS and M-LH), the Medical Faculty of Umeå University (BS and M-LH), the Council of Västerbotten (BS) and
Lions Cancer Research Fund (BS). The technical assistance of Yomna Rashad Farid is gratefully acknowledged.

\section{CONFLICT OF INTEREST}

The authors declare no conflict of interest.

\section{REFERENCES}

Bas A, Forsberg G, Hammarström S, Hammarström ML (2004) Utility of the housekeeping genes $18 \mathrm{~S}$ rRNA, $\beta$-actin and glyceraldehyde-3-phosphatedehydrogenase for normalization in real-time quantitative reverse transcriptase-polymerase chain reaction analysis of gene expression in human T lymphocytes. Scand J Immunol 59: 566-573.

Burkhardt AM, Tai KP, Flores-Guiterrez JP, Vilches-Cisneros N, Kamdar K, Barbosa-Quintana O, Valle-Rios R, Hevezi PA, Zuniga J, Selman M, Ouellette AJ, Zlotnik A (2012) CXCL17 is a mucosal chemokine elevated in idiopathic pulmonary fibrosis that exhibits broad antimicrobial activity. J Immunol 188: 6399-6406.

Chun E, Lavoie S, Michaud M, Gallini CA, Kim J, Soucy G, Odze R, Glickman JN, Garrett S (2015) CCL2 promotes colorectal carcinogenesis by enhancing polymorphonuclear myeloid-derived suppressor cell population and function. Cell Rep 12: 244-257.

Dwinell MB, Lugering N, Eckmann L, Kagnoff MF (2001) Regulated production of interferon-inducible T-cell chemoattractants by human intestinal epithelial cells. Gastroenterology 120: 49-59.

Erreni M, Bianchi P, Laghi L, Mirolo M, Fabbri M, Locati M, Mantovani A, Allavena P (2009) Expression of chemokines and chemokine receptors in human colon cancer. Methods Enzymol 460: 105-121.

Fahlgren A, Hammarström S, Danielsson Å, Hammarström ML (2003) Increased expression of antimicrobial peptides and lysozyme in colonic epithelial cells of patients with ulcerative colitis. Clin Exp Immunol 131: 90-101.

Gottfried E, Kunz-Schughart LA, Weber A, Rehli M, Peuker A, Muller A, Kastenberger M, Brockhoff G, Andreesen R, Kreutz M (2008) Expression of CD68 in non-myeloid cell types. Scand J Immunol 67: 453-463.

Hiraoka N, Yamazaki-Itoh R, Ino Y, Mizuguchi Y, Yamada T, Hirohashi S, Kanai Y (2011) CXCL17 and ICAM2 are associated with a potential anti-tumor immune response in early intraepithelial stages of human pancreatic carcinogenesis. Gastroenterology 140: 310-321. 
Jung HC, Eckmann L, Yang SK, Panja A, Fierer J, Morzycka-Wroblewska E, Kagnoff MF (1995) A distinct array of proinflammatory cytokines is expressed in human colon epithelial cells in response to bacterial invasion. $J$ Clin Invest 95: 55-65.

Lee WY, Wang CJ, Lin TY, Hsiao CL, Luo CW (2013) CXCL17, an orphan chemokine, acts as a novel angiogenic and anti-inflammatory factor. Am J Physiol Endocrinol Metab 304: E32-E40.

Li L, Yan J, Xu J, Liu CQ, Zhen ZJ, Chen HW, Ji Y, Wu ZP, Hu JY, Zheng L, Lau WY (2014) CXCL17 expression predicts poor prognosis and correlates with adverse immune infiltration in hepatocellular carcinoma. PLoS One 9: e110064.

Maravillas-Montero JL, Burkhardt AM, Hevezi PA, Carnevale CD, Smit MJ, Zlotnik A (2015) Cutting edge: GPR35/CXCR8 is the receptor of the mucosal chemokine CXCL17. J Immunol 194: 29-33.

Matsui A, Yokoo H, Negishi Y, Endo-Takahashi Y, Chun NA, Kadouchi I, Suzuki R, Maruyama K, Aramaki Y, Semba K, Kobayashi E, Takahashi M, Murakami T (2012) CXCL17 expression by tumor cells recruits $\mathrm{CD} 11 \mathrm{~b}+\mathrm{Gr} 1$ high F4/80- cells and promotes tumor progression. PLoS One 7: e44080.

Mu X, Chen Y, Wang S, Huang X, Pan H, Li M (2009) Overexpression of VCC-1 gene in human hepatocellular carcinoma cells promotes cell proliferation and invasion. Acta Biochim Biophys Sin 41: 631-637.

Öberg ÅN, Lindmark GE, Israelsson AC, Hammarström SG, Hammarström ML (2004) Detection of occult tumour cells in lymph nodes of colorectal cancer patients using real-time quantitative RT-PCR for CEA and CK20 mRNAS. Int J Cancer 111: 101-110.

Ohlsson L, Lindmark G, Israelsson A, Palmqvist R, Öberg A, Hammarström ML, Hammarström S (2012) Lymph node tissue kallikrein-related peptidase 6 mRNA: a progression marker for colorectal cancer. Br J Cancer 107: 150-157.

Rotondi M, Chiovato L, Romagnani S, Serio M, Romagnani P (2007) Role of chemokines in endocrine autoimmune diseases. Endocr Rev 28: 492-520.

Seliger B, Marincola FM, Ferrone S, Abken H (2008) The complex role of B7 molecules in tumor immunology. Trends Mol Med 14: 550-559.

Sitohy B, Hammarström S, Danielsson A, Hammarström ML (2008) Basal lymphoid aggregates in ulcerative colitis colon: a site for regulatory $\mathrm{T}$ cell action. Clin Exp Immunol 151: 326-333.

Uhlen M, Ponten F, Hober S, Bergstrom L, Takanen J, Nilsson P, von Feilitzen K, Lundberg E, Navani S (2014) Human Protein Atlas. Available at http://www.proteinatlas.org/ENSG00000189377-CXCL17/tissue.

Vassilatis DK, Hohmann JG, Zeng H, Li F, Ranchalis JE, Mortrud MT, Brown A, Rodriguez SS, Weller JR, Wright AC, Bergmann JE, Gaitanaris GA (2003) The G protein-coupled receptor repertoires of human and mouse. Proc Natl Acad Sci USA 100: 4903-4908.

Weibel ER (1979) Point Counting Methods. In: Sterological methods, Weibel ER (ed), Vol. 1. Academic Press: London, UK.

Weinstein EJ, Head R, Griggs DW, Sun D, Evans RJ, Swearingen ML, Westlin MM, Mazzarella R (2006) VCC-1, a novel chemokine, promotes tumor growth. Biochem Biophys Res Commun 350: 74-81.

Zlotnik A, Yoshie O (2012) The chemokine superfamily revisited. Immunity 36: 705-716.

(c) (1) (2) This work is licensed under the Creative Commons cc. national License. To view a copy of this license, visit http:// creativecommons.org/licenses/by-nc-sa/4.0/ 